\title{
VISUALIZATION AT THE MOUSE NEUROMUSCULAR JUNCTION OF A SUBMEMBRANE STRUCTURE IN COMMON WITH TORPEDO POSTSYNAPTIC MEMBRANES ${ }^{1}$
}

\author{
ROBERT SEALOCK
}

Department of Physiology and The Neurobiology Program, University of North Carolina, Chapel Hill, North Carolina 27514

Received October 9, 1981; Accepted January 21, 1982

\begin{abstract}
To test for submembrane structures common to postsynaptic membranes of muscle and electric tissue, mouse sternomastoid muscles were fixed in the presence of tannic acid under conditions such that a heavy layer of densely staining material was built up on plasma membranes. In thin section electron micrographs of such muscles, the hydrophobic portion of the bilayer and some membraneassociated structures appear in strong negative contrast. At the endplate, acetylcholine receptorrich membrane regions appear as a broad (14- to 15-nm) image approximately bisected by the thin $(\sim 2-\mathrm{nm})$ image of the bilayer. The extracellular half of the image arises from the receptor protein. The cytoplasmic half contains a distinct bar of contrasted material which is precisely co-extensive with the receptor image. Quantitative and direct visual comparisons show that the image is almost indistinguishable from that obtained by a similar method applied to isolated postsynaptic membranes from electric tissue of Torpedo californica (Sealock, R. (1982) J. Cell Biol. 92: 514-522). In the latter case, the bar probably arises from the 43,000 -dalton protein, a major peripheral membrane protein component of the isolated membranes. The results thus suggest that the 43,000-dalton protein in muscle and electric tissue forms similar structures and, conversely, that the structure in the isolated membranes retains the essential features of its in situ state.
\end{abstract}

An important new problem in the study of purified postsynaptic membranes from electric tissue concerns the localization and functions of protein components other than the cholinergic receptor. Recent studies of these membranes by thin section electron microscopy have produced evidence for nonreceptor components associated with the cytoplasmic surface of the membrane in regions of high receptor density (Sealock, 1980, 1982; Sobel et al., 1980; Cartaud et al., 1981). In one of these studies, membranes were prepared for microscopy under conditions such that tannic acid in the fixative caused an extensive build-up of stainable material around individual vesicles (Sealock, 1982). This unusual material seems to infiltrate molecular structures much as conventional negative stains do so that the membrane and associated structures are revealed in strong negative contrast. In transverse sections through regions of high receptor density, the image of the membrane is unusually broad (13 to $14 \mathrm{~nm}$ ) and approximately bisected by the image of

I wish to thank Mr. Michael Spillane for his excellent technical assistance and Dr. S. D. Flanagan for making information available to me prior to publication. This work was supported by National Institutes of Health Grant NS15293. the lipid bilayer. The outer half of the image could be ascribed to the well known portions of the receptor molecule which project above the membrane surface (Cartaud et al., 1978; Heuser and Salpeter, 1979). The most strongly contrasted feature of the inner (i.e., cytoplasmic) half of the image appeared as a bar or line lying 4 to $6 \mathrm{~nm}$ from the center of the bilayer. Since the bar is eliminated by extraction of the membranes at $\mathrm{pH} 11$ prior to fixation, it was tentatively ascribed to the socalled 43,000-dalton protein, ${ }^{2}$ a major alkaline-extractable protein which is believed to be associated specifically with the postsynaptic membrane (Sobel et al., 1977; Neubig et al., 1979; Elliott et al., 1980).

The membranes used in the above study were isolated by vigorous homogenization of electric tissue followed by density gradient fractionation at nearly zero ionic

\footnotetext{
${ }^{2}$ The term " 43,000 -dalton protein" in this paper refers to membranebound protein material which migrates as a single band on one-dimensional polyacrylamide-SDS gels with $M_{\mathrm{r}} \approx 43,000$ and is quantitatively extracted at $\mathrm{pH} 11$. Although this material has behaved as a single protcin species in our experiments others have found that the band may, in fact, contain multiple species (Barrantes et al., 1980; Gysin et al., 1981).
} 
strength (Sobel et al., 1977). This procedure, as carried out in this laboratory, leads to the loss of cytoplasmic filaments and dense material which are associated with the membrane in situ (Rosenbluth, 1975; Sealock, 1980; Cartaud et al., 1981). Thus, the relationship of the inner surface image to the structure of the membrane in situ remained unclear. In this study, I have sought both a partial resolution of this problem and a comparison of the postsynaptic membranes of electric tissue and skeletal muscle by application of tannic acid-mediated negative contrasting to the mouse motor endplate. This approach was prompted by the many similarities between muscle and electric tissue (see Sealock and Kavookjian, 1980) but has gained in interest because of the immunofluorescent demonstration that anti-43,000-dalton antibodies bind to the rat neuromuscular junction with a distribution similar to that of the receptor (Froehner et al., 1981). The results show that the negatively contrasted images of the two postsynaptic membranes are qualitatively and quantitatively similar. In particular, the inner surface bar is a prominent feature of the image in regions of high receptor density (i.e., at the tops of the junctional folds) and it is absent elsewhere. These results suggest that the bar does, in fact, reflect structures present in situ and that detailed morphological study of the isolated membranes from electric tissue can have direct relevance to study of the endplate.

\section{Materials and Methods}

The sternomastoid muscle of the mouse was selected for these experiments because of its relatively narrow endplate zone. The fixative was physiological salt solution ( $130 \mathrm{~mm} \mathrm{NaCl}, 6 \mathrm{mM} \mathrm{KCl}, 3 \mathrm{~mm} \mathrm{CaCl}, 1 \mathrm{mM} \mathrm{MgCl}_{2}$, $1 \mathrm{~mm}$ sodium phosphate) buffered with $10 \mathrm{~mm}$ sodium cacodylate and supplemented with $2 \%$ glutaraldehyde (Polysciences EM grade, $8 \%$ stock) and $0.5 \%$ tannic acid (the low molecular weight product from Mallinckrodt; Simionescu and Simionescu, 1976). The $\mathrm{pH}$ was adjusted to 7.2 after the mixing of all components. The muscles were exposed in ether-anesthetized mice, flooded with fixative, excised, and pinned out under additional fixative. After $30 \mathrm{~min}$ at room temperature, thin $(\sim 0.8-\mathrm{mm})$ transverse slices were taken from the endplate zone with a razor blade. The slices were fixed for an additional 30 min at room temperature and then shaken for $18 \mathrm{hr}$ in fixative at $4^{\circ} \mathrm{C}$ in cold salt solution, postfixed for $2 \mathrm{hr}$ at $4^{\circ} \mathrm{C}$ with $0.5 \%$ osmium tetroxide in buffered salt solution, washed in water, dehydrated with graded alcohols, and infiltrated with Epon 812.

After polymerization, the slices were mounted on Epon blanks so that they could be sectioned parallel to their faces. Endplates were located in $0.3-\mu \mathrm{m}$ sections taken from the immediate surface of the slices. Silver sections of endplates were poststained with $2 \%$ uranyl acetate in water for $10 \mathrm{~min}$, followed by lead citrate (Reynolds, 1963) for $10 \mathrm{~min}$.

Micrographs were taken at $\times 31,600$ with a Zeiss EM $10 \mathrm{~A}$ microscope operated at $60 \mathrm{kV}$ with a $60-\mu \mathrm{m}$ objective aperture.

For quantitative measurements, clear, well contrasted regions which appeared to have been sectioned transversely, as judged principally by a thin middle lamina, were printed at $\times 300,000$. Lines were drawn along the outer and inner edges of the images, and the perpendicular distances from the center of the bilayer image to the outer line $\left(l_{0}\right)$ and to the inner line $\left(l_{i}\right)$ and the overall width $\left(l_{o}+l_{i}\right)$ were measured. Only one set of measurements was taken per usable stretch of membrane for a total of 33 measurements.

\section{Results}

In the preliminary phase of this study, tannic acidmediated negative contrasting of muscle fibers was induced by immersion of intact muscies in fixatives containing tannic acid. The resulting negative contrasting material was, however, restricted invariably to the outermost muscle fibers, making the location of endplates very inefficient. Extension of the contrasting to the interior of the muscle by perfusion with fixatives containing tannic acid was not tried, since several previous attempts with electric tissue (R. Sealock, unpublished experiments) had established that, at least in that tissue, the intensity of the negative contrasting obtained by perfusion fixation was always weaker than that obtained by immersion fixation. I chose, therefore, to incubate thin, transverse slices of preliminarily fixed muscle overnight in fixative containing tannic acid. Fibers throughout the cross-section of the muscle were contrasted by this procedure, but the contrasting extended only a short distance into the slices. Preliminary experiments also established that the depth and strength of the contrasting were not increased greatly by the use, in various combinations, of high concentrations (6 to $8 \%$ ) of tannic acid, of $0.1 \%$ saponin to permeabilize the membranes (Seeman, 1967), and of hypotonic fixatives (Ohtsuki et al., 1978). Hence, the results reported here were taken from thin sections made from the faces of slices which had been fixed extensively in the presence of $0.5 \%$ tannic acid. Since the slices were taken from endplate zones, one or more endplates usually could be found by light microscopy in each face of a slice.

A typical negatively contrasted neuromuscular junction is shown in Figure 1A. 'The negative contrasting material was particularly dense on the extracellular surfaces of membranes, on collagen fibers and basal laminae, and in the primary and secondary synaptic clefts. Structures in the interior of muscle cells most often were positively contrasted in the conventional manner or were seen in weak negative contrast. This was true even though the sections were made very near the cut ends of the cells. Frequently, however, there was strong negative contrasting inside of nerve terminals and overlying Schwann cells as in Figure 1A. Nerve terminals were particularly susceptible to damage during the slow fixation as shown, for example, by the multilamellar structure in Figure $1 A$, but deformation or stretch of the muscle plasma membranes did not occur as indicated by their completely normal relationship to the muscle basal lamina and the lack of blebbing.

The membranes which bound the synaptic cleft are shown at higher magnification in Figure $1 B$. The inner and outer surfaces of the nerve terminal membrane and the outer surface of the postsynaptic membrane are strongly contrasted, while a somewhat lower degree of 

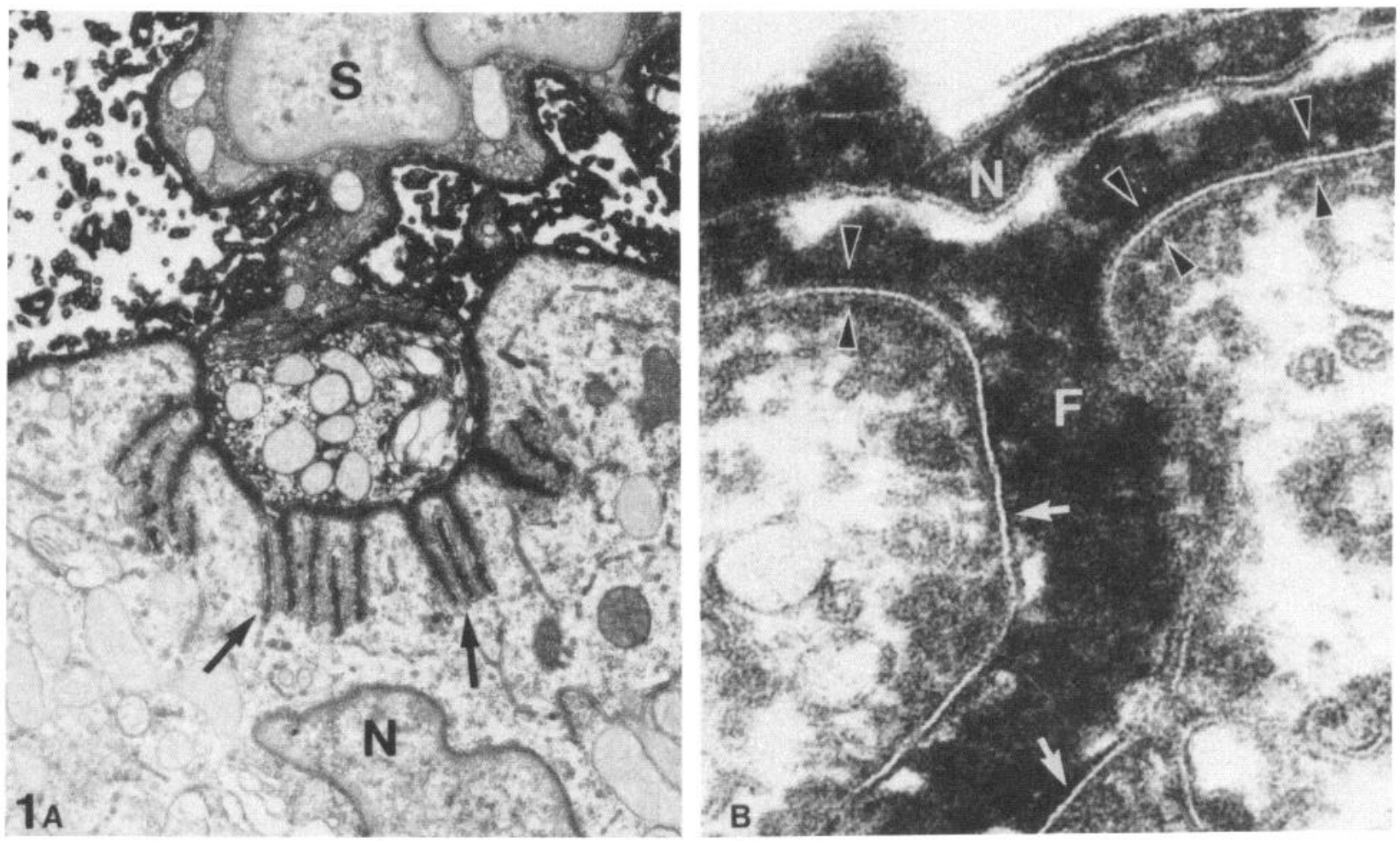

Figure 1. The negatively contrasted neuromuscular junction. A, A typical junction showing the strong negative contrasting of extracellular elements, particularly collagen fibrils and basal laminae, even in the depths of the junctional folds (arrows). The interiors of the overlying Schwann cell $(S)$ and the muscle fiber are poorly contrasted. Mitochondria are not contrasted. This view includes a muscle nucleus $(N) . B$, The nerve terminal $(N)$ and postsynaptic membranes at the mouth of a junctional fold $(F)$. The juxtaneural postsynaptic membrane has negatively contrasted specializations on both surfaces (arrowheads), while the membrane in the deeper portion of the folds appears only as a thin line (arrows). Magnifications: $A, \times 21,400 ; B, \times 210,000$.

contrasting occurs on the cytoplasmic surface of the postsynaptic membrane. The common feature in the images of all membrane species in muscle and electric tissue (Sealock, 1982) is a thin ( 2-nm), strongly contrasted line which arises by exclusion of the contrasting material by the hydrophobic portion of the bilayer. In addition to this line, the image of the postsynaptic membrane at the tops of the folds (i.e., the juxtaneural membrane) includes distinct, negatively contrasted structures associated with both the inner and outer membrane surfaces. Several examples are shown in Figures $1 B$ and $2, A$ to $E$. These images can best be appreciated by viewing from the side, sighting almost along the tangent to the page. In contrast to the juxtaneural membrane, the thin line is the only image given by membranes in nerve teminals (Fig. $1 B$ ), the lower portions of junctional folds (arrows in Fig. $1 B$ ), extrajunctional regions of muscle fibers (Fig. $2 F$ ), and Schwann cells (not shown). In fact, a thorough study of the tissue failed to uncover any other membrane species having strongly contrasted specializations on either surface. The juxtaneural membrane is thus a morphologically unique membrane species in negatively contrasted muscle.

At higher magnification, the inner and outer surfaces of the juxtaneural membrane are easily distinguished (Fig. 2, $A$ to $E$ ). The structure on the outer surface appears as roughly rectangular projections or as a band of contrasted material with a rather poorly defined internal structure. The center-to-center separation of the projections is $\sim 9 \mathrm{~nm}$, similar to the value ( 8 to $9 \mathrm{~nm}$ ) found with negatively contrasted postsynaptic membranes from Torpedo californica (Sealock, 1982). At the cytoplasmic surface, the most strongly contrasted and most consistent feature of the image appears as a roughly linear grouping of points of strong contrasting which may fuse into a distinct bar or line (Fig. 2, $A$ to $E$ ). This bar forms the cytoplasmic edge of the image and usually is separated from the bilayer image by a thin intermediate zone which is wholly or partially filled with contrasting material (Figs. $1 B$ and $2, A$ to $E$ ). In places, distinct substructures give the appearance of connecting the bilayer image with the bar (Fig. $2 \mathrm{C}$ ), but more commonly, the intermediate zone contains an amorphous image of relatively weak contrasting (Fig. $2 D$ ). The appearance of the inner surface specialization as a bar can be enhanced by the underfocusing of the microscope, but in the most convincing cases, such as Figures $1 B$ and $3, A$ and $E$, it remains throughout a through-focus series of micrographs (data not shown) and therefore does not arise primarily through inappropriate use of the microscope.

The outer surface image in muscle can be identified with the acetylcholine receptor protein on the basis of several lines of evidence: (1) it is restricted to the juxtaneural membrane, which is the only site of high receptor density in innervated muscle (Fertuck and Salpeter, 1976); (2) it is similar to the outer surface image obtained with membranes from $T$. californica, where the identification is conclusive (Sealock, 1982) (Fig. 3); (3) the 
receptor is believed to project above its membrane in muscle as it does in electroplax (Rosenbluth, 1974; Rash and Ellisman, 1974; Hirokawa and Heuser, 1980); and (4) the receptor is densely packed and occurs in rows in the muscle postsynaptic membrane (Rash and Ellisman, 1974; Hirokawa and Heuser, 1980). Hence, the outer surface image consists of simple projections when the receptor rows are aligned with the optical axis of the microscope and as a band when they are viewed partially from the side.

At the present time, the inner surface image can be identified only through reference to the isolated membranes. Figure 3 shows the qualitative similarities between the two images. The high degree of similarity suggests that they arise from corresponding structures, even though the muscle membrane is underlaid by a dense, filamentous material which extends much further from the membrane surface than the negatively contrasted structure (Figs. $1 B$ and 2; Couteaux and Pécot-
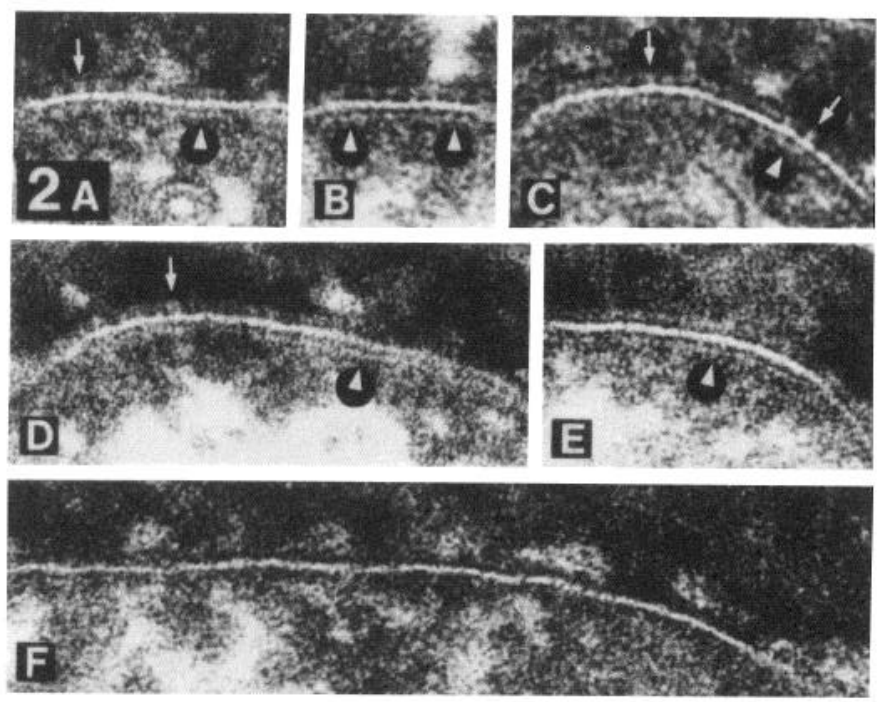

Figure 2. Negatively contrasted muscle membranes at higher magnification. The upper surface in each picture is the outer surface of the membrane. $A$ to $E$, Juxtaneural postsynaptic membrane. The outer surface image often contains distinct projections (arrows). The inner surface image appears as a line or bar of strongly contrasted points (arrowheads). Occasional structures appear to join the bilayer image with the bar (arrowhead in $C$ ). $F$, A typical stretch of extrajunctional membrane. No regularly occurring, negatively contrasted structures are apparent. Magnifications: $\times 250,000$.
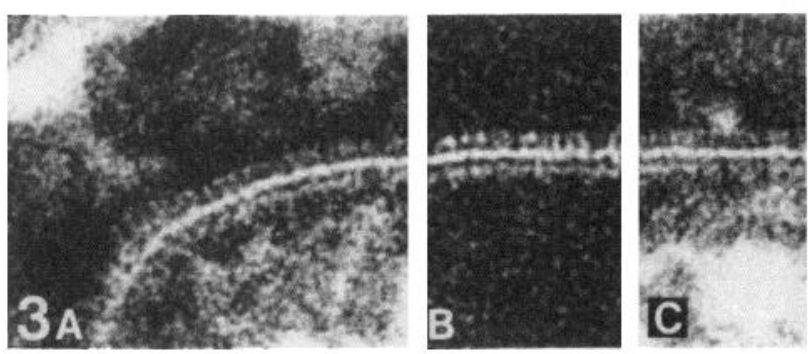

Dechavassine, 1968; Rosenbluth, 1974; Heuser, 1980; Hirokawa and Heuser, 1980), while any such material in the electroplax (Sealock and Kavookjian, 1980; Cartaud et al., 1981) is removed during membrane isolation (Sealock, 1980). The inner surface bar in membranes from Torpedo is largely eliminated by extraction of the membranes at $\mathrm{pH} 11$ prior to fixation, while the outer surface image is nearly unchanged (Fig. $3 D$ ). The 43,000 -dalton protein appeared to be the only major protein removed by extraction from the membranes used in the preparation of Figure 3, $B$ and $D$ (Sealock, 1982) as expected (Neubig et al., 1979). However, the possibility that the membranes contained an extractable, major protein which was not detected by gel electrophoresis could not be eliminated entirely. Hence, the bar seen with Torpedo membranes was tentatively identified with the 43,000 -dalton protein.

The images of the muscle and isolated membranes are also quantitatively similar. Table I shows that there is good agreement among the widths of the outer $\left(l_{o}\right)$ and inner $\left(l_{i}\right)$ halves of the images obtained in muscle and the two species of electric tissue studied previously. In all three cases, the image is approximately symmetrical with respect to width about the layer image $\left(l_{o} / l_{i} \approx 1.0\right)$. This consistent finding suggests that the slight increase in the overall widths of the images in going from Torpedo to Narcine to muscle reflects systematic variations, such as section thickness and contrasting intensities of the samples rather than differences in molecular sizes. Hence, the negatively contrasted portion of the membrane in muscle is probably somewhat narrower than the measured $14.7 \mathrm{~nm}$.

TABLE I

Dimensions of negatively contrasted postsynaptic membranes

\begin{tabular}{lccc}
\hline & Torpedo $^{\alpha}$ & Narcine $^{a}$ & Muscle \\
\hline & & $n m$ & \\
$l_{o}{ }^{b}$ & $6.3^{c}$ & 6.8 & 7.3 \\
$l_{i}{ }^{c}$ & 6.4 & 6.9 & 7.4 \\
$l_{o}+l_{i}$ & 12.8 & 13.7 & 14.7 \\
& & & \\
$l_{o} / l_{i}$ & 1.0 & 1.0 & 1.0 \\
\hline
\end{tabular}

${ }^{a}$ From Sealock, 1982.

${ }^{b}$ The distance from the center of the bilayer image to the outermost edge of the overall image.

'Standard deviations of the means range from 9 to $15 \%$ for all measurements.

${ }^{d}$ The distance from the center of the bilayer image to the innermost edge of the overall image.
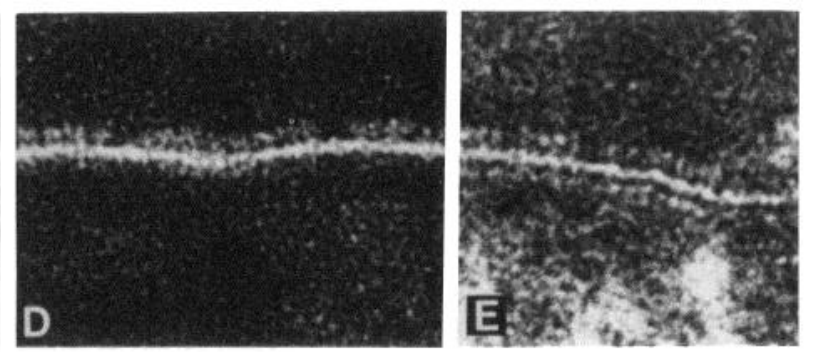

Figure 3. Comparison of the membrane in muscle $(A, C$, and $E)$ with intact $(B)$ and alkaline-extracted $(D)$ membranes from $T$. californica. The micrographs in $B$ and $D$ are taken from a previous study (Sealock, 1982; reprinted with permission from The Rockefeller University Press). This figure, like Figure 2, is best viewed from the side at an angle of $\sim 30^{\circ}$ to the plane of the page. Magnifications: $\times 350,000$. 


\section{Discussion}

The results of this study show that the cytoplasmic surfaces of the acetylcholine receptor-rich, postsynaptic membranes in mouse skeletal muscle and after isolation from electric tissue give similar images after tannic acidmediated negative contrasting. This result could have been anticipated from published micrographs (Rosenbluth, 1974; Heuser, 1980) in which the (positively contrasted) receptor-rich membrane in muscle appears to have a thick inner lamina like that in electric tissue and membranes derived from it (Sealock, 1980). The use of negative contrasting to investigate the inner surface has the particular advantage, however, that it reports more on the concentration of protein in a given region than on the ability of the region to bind heavy metals. Conventional negative staining is inconvenient for this purpose, since it rarely gives an unobstructed view of the inner surface of isolated membrane vesicles (but see an example in Cartaud et al., 1978), and its application to muscle would require the use of ultrathin frozen sections (Tsuji, 1978). On the other hand, tannic acid-mediated negative contrasting for thin section electron microscopy affords simultaneous but separate views of both surfaces in unlimited quantity, and it is easily extended to muscle.

The image of the postsynaptic membrane obtained by negative contrasting of muscle is best analyzed by comparison to the image of isolated membranes from electric tissue for three reasons. First, the mechanism by which the contrasting material accumulates around structures and is excluded from some portions of them is not known with certainty. However, in the study of isolated membranes, 8-nm rosette-like structures which could be reliably identified as individual receptor molecules could be seen in areas where the plane of the membrane lay within and parallel to the plane of the section (Sealock, 1982). From these observations, it was concluded that the mechanism of image formation, at least as far as the receptor is concerned, must be similar to that in conventional negative staining. Furthermore, these observations showed that the inherent resolution in the method is surprisingly high, although much of this resolution is sacrificed in practice due to superposition of contrasted structures through the thickness of the sections. Secondly, the internal and external environments of the isolated membranes can be controlled and made identical, thereby assuring optimal contrasting of both sides. The quality of the negative contrasting obtained with muscle, where many of the chemical conditions are fixed, has been consistently inferior (Fig. 3). Finally, the isolated membranes prepared in this laboratory do not carry extensive filamentous material like that found in muscle so that the material need not be invoked to offer an explanation of the observed image. The close similarities between the inner surface images of muscle and electric tissue membranes therefore suggest that they have their origins in homologous structures and that the structure is relatively little altered, at least in its gross features, by the membrane isolation procedure.

A tentative identification of the inner surface bar in biochemical terms is possible through the alkaline extraction experiment. Since the bar is strongly contrasted in the isolated membrane, it must be true not only that its individual elements exclude the contrasting material well but also that they occur at rather high density. Hence, these elements are likely to be major protein components of the membrane. The 43,000-dalton protein is probably the only major protein extracted from the membranes at $\mathrm{pH} \mathrm{11}$, and simple calculation suggests that there are sufficient amounts of it on the membranes to account for the observed image (Sealock, 1982). The evidence thus suggests that the 43,000 -dalton protein may be the major component of the structure which gives rise to the bar in electric tissue and, by extension, in muscle. This conclusion does not, of course, exclude the possibility that the structure contains other protein as well.

Correlation of a cytoplasmic structure with the 43,000 dalton protein also is supported by other, independent experiments. The 43,000 -dalton protein on isolated membranes is not modified by trypsin (Wennogle and Changeux, 1980) or lactoperoxidase-catalyzed iodination (St. John et al., 1982; St. John, 1980) unless steps, such as pretreatment with saponin, are taken to cause reagents to enter the sealed, right-side-out vesicles formed by postsynaptic membranes. At the rat neuromuscular junction, the distributions of reactivities to antibodies against Torpedo receptor and against the 43,000-dalton protein are identical at the light microscopic level (Froehner et al., 1981). The latter experiments were carried out on frozen sections so that the side of the membranc to which the anti-43,000-dalton antibodies bound could not be determined. All of the available evidence is thus consistent with the hypothesis that the 43,000-dalton protein is associated with the cytoplasmic surface of the membrane and precisely confined to receptor-rich regions.

Changeux and co-workers (Cartaud et al., 1981) have correlated a somewhat different structure with the 43,000-dalton protein in membranes from electric tissue of Torpedo marmorata. They find that receptor-rich regions of these membranes, when fixed in the presence of tannic acid for positive contrasting, contain large "condensations" of material associated with the cytoplasmic surface and extending as much as $40 \mathrm{~nm}$ from the center of the bilayer image. The condensations are eliminated by alkaline extraction so that they have been identified tentatively with the 43,000-dalton protein. Extrapolation of this result to muscle would suggest that the extensive filamentous material underlying the receptor-rich membrane is the site of 43,000 -dalton protein localization. However, similar condensations occur only occasionally in vesicles prepared according to method of Sobel et al. (1977) from tissue of Narcine brasiliensis and $T$. californica (Sealock, 1980, 1982), even though these preparations have a full complement of the 43,000 dalton protein (cf., Sobel et al., 1977, and Sealock, 1982). An inner surface bar like that seen here is a prominent feature in membranes from $T$. marmorata subjected to tannic acid-mediated negative contrasting (Sealock, 1982). Hence, these condensations appear to be a most interesting postsynaptic structure now subject to biochemical analysis but possibly not related to the 43,000 dalton protein.

Submembrane densities and specializations at synapses are of considerable general importance and interest in neurobiology. Among other functions, those on the postsynaptic side frequently are supposed to serve some role in maintaining high densities of neurotransmitter 
receptors in the postsynaptic membrane. The 43,000dalton protein appears to be one cytoplasmic structure for which direct experimental evidence for such a role is begimning to accumulate. Thus, the acetylcholine receptor protein gains rapid rotational mobility (Rousselet et al., 1979; Lo et al., 1980) and assumes a more disordered distribution (Barrantes et al., 1980) after alkaline extraction of isolated postsynaptic membranes, and it becomes further dispersed in the plane of the membrane if alkaline-extracted, but not intact, membranes are caused to fuse with liposomes (Cartaud et al., 1981). These data suggest, but do not establish, that the 43,000-dalton protein acts to limit lateral diffusion of the receptor, presumably by direct association with the cytoplasmic ends of receptor molecules. Thus, the study of nicotinic synapses appears to have entered an exciting phase in which nonreceptor components, suspected or not to exist at synapses of interest, can be discovered and indirectly tested for function via study of electric tissue.

\section{References}

Barrantes, F. J., D. -C. Neugebauer, and H. P. Zingsheim (1980) Peptide extraction by alkaline treatment is accompanied by rearrangement of the membrane-bound acetylcholine receptor from Torpedo marmorata. FEBS Lett. 112: 73-78.

Cartaud, J., E. L. Benedetti, A. Sobel, and J. -P. Changeux (1978) A morphological study of the cholinergic receptor protein from Torpedo marmorata in its membrane environment and in its detergent-extracted, purified form. J. Cell Sci. 29: $313-337$.

Cartaud, J., A. Sobel, A. Rousselet, P. F. Devaux, and J. -P. Changeux (1981) Consequences of alkaline treatment for the ultrastructure of the acetylcholine-receptor rich membranes from Torpedo marmorata electric organ. J. Cell Biol. 90: 418-426.

Couteaux, R., and M. Pécot-Dechavassine (1968) Particularités structurales du sarcoplasma sous neural. C. R. Acad. Sci. [D] (Paris) 266: 8-10.

Elliott, J., S. G. Blanchard, W. Wu, J. Miller, C. D. Strader, P. Hartig, H. -P. Moore, J. Racs, and M. A. Raftery (1980) Purification of Torpedo californica postsynaptic membranes and fractionation of their constituent proteins. Biochem. J. 185: $667-677$.

Fertuck, H. C., and M. M. Salpeter (1976) Quantitation of junctional and extrajunctional acetylcholine receptors by electron microscope autoradiography after 125 -I- $\alpha$-bungarotoxin binding at mouse neuromusuclar junctions. J. Cell Biol. 69: 144-158.

Froehner, S. C., V. Gulbrandsen, C. Hyman, A. Y. Jeng, R. R. Neubig, and J. B. Cohen (1981) Immunofluorescence localization at the mammalian neuromuscular junction of the $M_{r}$ 43,000 protein of Torpedo post-synaptic membranes. Proc. Natl. Acad. Sci. U. S. A. 78: 5230-5234.

Gysin, R., M. Wirth, and S. D. Flanagan (1981) Structural heterogeneity and subcellular distribution of nicotinic synapse-associated proteins. J. Biol. Chem. 256: 11373-11376.

Heuser, J. E. (1980) 3-D visualization of membrane and cytoplasmic specializations at the frog neuromuscular junction. In Ontogenesis and Functional Mechanisms of Peripheral Synapses, J. Taxi, ed., pp. 139-155, Elsevier/North-Holland Biomedical Press, Amsterdam.

Heuser, J. E., and S. R. Salpeter (1979) Organization of acetylcholine receptors in quick-frozen, deep-etched and rotoryreplicated Torpedo postsynaptic membrane. J. Cell Biol. 82: 150-173.

Hirokawa, N., and J. E. Heuser (1980) Possible anchoring structures for the organized arrays of receptors seen at neuromuscular junctions. J. Cell Biol. 87: 75a.

Lo, M. M. S., P. B. Garland, J. Lamprecht, and E. A. Barnard (1980) Rotational mobility of the membranc-bound acetylcholine receptor of Torpedo electric organ measured by phosphorescence depolarization. FEBS Lett. 111: 407-412.

Neubig, R. R., E. Krodel, N. D. Boyd, and J. B. Cohen (1979) Acetylcholine and local anesthetic binding to Torpedo nicotinic postsynaptic membranes after removal of nonreceptor peptides. Proc. Natl. Acad. Sci. U. S. A. 76: 690-694.

Ohtsuki, I., R. M. Manzi, G. E. Palade, and J. D. Jamieson (1978) Entry of macromolecular tracers into cells fixed with low concentrations of aldehydes. Biol. Cell. 31: 119-126.

Rash, J. E., and M. H. Ellisman (1974) Studies of excitable membranes. I. Macromolecular specializations of the neuromuscular junction and the nonjunctional sarcolemma. J. Cell Biol. 63: 567-586.

Reynolds, E. S. (1963) The use of lead citrate at high $\mathrm{pH}$ as an electron-opaque stain in electron microscopy. J. Cell Biol. 17: 208-212.

Rosenbluth, J. (1974) Substructure of amphibian motor endplate. Evidence for a granular component projecting from the outer surface of the receptive membrane. J. Cell Biol. 62: 755-766.

Rosenbluth, J. (1975) Synaptic membrane structure in Torpedo electric organ. J. Neurocytol. 4: 697-712.

Rousselett A., J. Cartaud, and P. F. Devaux (1979) Importance des interactions proteine-proteine dans le maintien de la structure de fragments excitable de l'organe électrique de Torpedo marmorata. C. R. Acad. Sci. [D] (Paris) 289: 461463.

Sealock, R. (1980) Identification of regions of high acetylcholine receptor density in tannic acid-fixed postsynaptic membranes from electric tissue. Brain Res. 199: 267-281.

Sealock, R. (1982) Cytoplasmic surface structure in postsynaptic membranes from electric tissue visualized by tannic acid-mediated negative contrasting. J. Cell Biol. 92: 514-522.

Sealock, R., and A. Kavookjian (1980) Postsynaptic distribution of acetylcholine receptors in electroplax of the torpedine ray, Narcine brasiliensis. Brain Res. 190: 81-93.

Seeman, P. (1967) Transient holes in the erythrocyte membrane during hypotonic hemolysis and stable holes in the membrane after lysis by saponin and lysolecithin. J. Cell Biol. 31: 55-70.

Simionescu, N., and M. Simionescu (1976) Galloylglucoses of low molecular weight as mordant in electron microscopy. 1. Procedure, and evidence for mordanting effect. J. Cell Biol. 70: 608-621.

Sobel, A., M. Weber, and J. -P. Changeux (1977) Large scale purification of the acetylcholine receptor protein in its membrane-bound and detergent-extracted forms from Torpedo marmorata electric organ. Eur. J. Biochem. 80: 215-224.

Sobel, A., T. Heidmann, J. Cartaud, and J. -P. Changeux (1980) Reconstitution of a functional acetylcholine receptor. Polypeptide chains, ultrastructure, and binding sites for acetylcholine and local anesthetics. Eur. J. Biochen. 110: 13-33.

St. John, P. A. (1980) Ultrastructural and biochemical studies of the acetylcholine receptor of Torpedo californica. Ph.D. thesis, Harvard University, Cambridge, MA.

St. John, P. A., S. C. Froehner, D. A. Goodenough, and J. B. Cohen (1982) Nicotinic postsynaptic membranes from Torpedo: Sidedness, permeability to macromolecules, and topography of major polypeptides. J. Cell Biol. 92: 333-342.

Tsuji, S. (1978) Ultracryotomy of nerve-electroplaque synapses for immunocytochemistry. J. Neurocytol. 7: 381-389.

Wennogle, L. P., and J. -P. Changeux (1980) Transmembrane orientation of proteins present in acetylcholine receptor-rich membranes from Torpedo marmorata studied by selective proteolysis. Eur. J. Biochem. 106: 381-383. 